his close associates. The conversion of this school to a neo-Darwinian attitude by their own discoveries in genetics and karyology, powerfully aided by their openness to ideas and visitors from abroad, was, however, only partial in some cases because of the difficulties of extending genetical findings to macroevolutionary phenomena, including speciation. Mayr makes an especially important contribution in emphasizing that the synthesis was a synthesis; it was extremely difficult for many years to reconcile Darwinism and the new science of genetics, and it was systematists in particular who contributed the concepts of adaptive geographical variation, variation in whole populations under environmental selection, and partly adaptive speciation (a macroevolutionary process). Yet it must be added that it was largely the wholly unjustified insistence of many systematists that characters of species were nonadaptive that misled many of the earlier evolutionists into doubts about the efficacy of natural selection and the continuity of micro- and macroevolutionary phenomena.

Equally fascinating is the comparison between subjects. Botany (not the botanical part of genetics) was almost as poor a contributor among subjects as France among countries, and Ledyard Stebbins's article is as thought-provoking as Boesiger's or Limoges'.

When one stands back from it all, several major thoughts come to mind. The difficulties are highly instructive, but little more than one would expect in any intellectual controversy; indeed Simpson is probably right in indicating that given the human character, the synthesis was achieved about as fast as could be expected. But some topics are hardly touched on. I suspect (in a few instances, I know) that religious considerations came first, even if they were seldom expressed, in some scientists' minds, and conditioned heavily what they were prepared to accept scientifically. Under this heading I include humanism when it refuses the application of the synthesis to mankind, and of course Marxism with its leaning to some form of Lamarckism (only too well documented in this book).

Secondly, and allied to the preceding, the role of chance as an explanatory factor is hardly touched on - yet, on the one hand, as a means of explaining away inconvenient phenomena it has been invaluable as an alternative to natural selection; on the other, it has added to the revulsion of many people against natural selection that what the process has to work on is the effects of mere chance.

But lastly, there is almost no indication in the book that the recognition of natural selection as the major (or nearly exclusive) agent of evolution was ever due to any work on natural selection in the wild, except very indirectly. A simple-minded (or extremely intelligent) Martian might well think that if it was debated whether natural selection operated in the wild, the thing to do was to go and look for it. Chetverikov might have done so if politicians had let him; Haldane thought it much too difficult. The whole debate over the efficiency of natural selection in the wild was conducted by argument over indirect evidence, and indeed to a large extent it still is.

The present book contains little material towards a history of actual field-work directly on natural selection, except for E.B. Ford's contribution - and perhaps rightly, since it seems not to have affected the synthesis. It does contain valuable hints towards a history of why no one has attempted it - for example, Lewontin's statement that "Wright's notion that random processes allow the exploration of the field of gene frequencies ... frees the evolutionist from having to ask such questions as why did some Ceratopsian dinosaurs have three horns and some have two and some have a frill and some not?". Of course it does nothing of the sort except to those who want it to. It was not shown in the first place that the development of different ways of fighting was due to any random process, except on the presumptuous assertion "Because I can see no sense in this phenomenon, not having worked on it, therefore it must be random". The use of random processes in explanation even at the present day is rather like John Henry Newman's use of St Augustine's text to precipitate him into the Roman Catholic church (see Geoffrey Faber's Oxford Apostles) - using a bad reason for doing what we intend to anyway.

A.J.Cain is Derby Professor of Zoology in the University of Liverpool.

\title{
Avian evolution transcends philately
}

\section{Alec Panchen}

The Age of Birds. By Alan Feduccia. Pp.208. ISBN 0-674-00975-4. (Harvard University Press: 1980.) £12, \$20.

OF ALL those who concern themselves with the palaeontology and evolution of vertebrate animals, it is arguable that bird palaeontologists have taken on the most difficult task. The anatomical uniformity of the majority of bird species is such that the identification of their individual fossil bones varies between difficult and impossible; further, there are numbers of cases (some cited by Feduccia) in which the avian status of particular specimens is still a matter for debate. It is probably for these reasons that while popular books on dinosaurs are legion, a book on bird palaeontology is unusual despite the innumerable amateur ornithologists that are the mainstay of almost every natural history society. One would hope, therefore, that there was a market for a popular book like Feduccia's as evidence that at least some of these amateurs have interests extending beyond the prevalent stamp-collecting approach to bird watching.

On the whole Feduccia serves his potential audience well. However, his opening chapter tends to hop about its subject matter in a manner reminiscent of small birds themselves, starting with a scene-setting paragraph on Archaeopteryx - geologically the oldest as well as the most famous of all bird fossils - but then switching to bird anatomy, "Darwin's finches", adaptive radiation, the concepts of homology and analogy, the reconstruction of phylogeny and the geological time scale, before settling on an account of the several finds of Archaeopteryx, with useful photographs of each specimen.

In his second chapter he gives an account of theories of the evolutionary origin of birds, a fiercely debated subject still. When dealing with controversial issues Feduccia is usually sensible and it is not his fault that at least one of the principal protagonists in this debate has changed sides since the chapter was written. Following chapters deal with the evolution of flight and then with the fossil history (such as it is) and evolution of all the major groups of birds.

Feduccia has been in the forefront of some of the phylogenetic work he describes and much of the book is authoritative. However, particularly in the early chapters, there are some things to take exception to. The layman's naive view of the course of evolution, as a highway from simple organisms to human beings with less important byways branching off, will be reinforced by statements such as "ornithischians [a dinosaur group] were highly specialised herbivores and far too removed from the main line to have given rise to any other major group"'. It will be similarly reinforced by the use of "Age of Reptiles", "Age of Mammals and Birds" and so on, as in "The cotylosaurs [the earliest reptiles in the author's (outmoded) usagel appeared long before the Age of Reptiles ...". There are also a few obvious errors - how, for example, can the two views of the original Archaeopteryx feather, pictures on p.12, be "main slab" and "counterslab" when they are not mirror images of one another? Also, the patagium (flying membrane) of the living flying lizard genus Draco does not stretch "between the forelimb and hindlimb" (p.40): it is supported by elongate ribs alone.

On the whole, though, the book is easy and pleasant to read. The style is clear, concise and interesting, albeit with some infelicities - "Members of this classifica- 
tion ..." (i.e. taxon); “. . . third alternative ..." - and the chapters are short. The bibliography is excellent; here Feduccia refuses to "talk down" to the reader and quotes every reference, not just "further reading". However, the illustrations although numerous are often disappointing. They include black and white photographs of specimens and localities, and a number of frankly mediocre original drawings by several hands, the low standard of which is emphasized by some of the splendid and

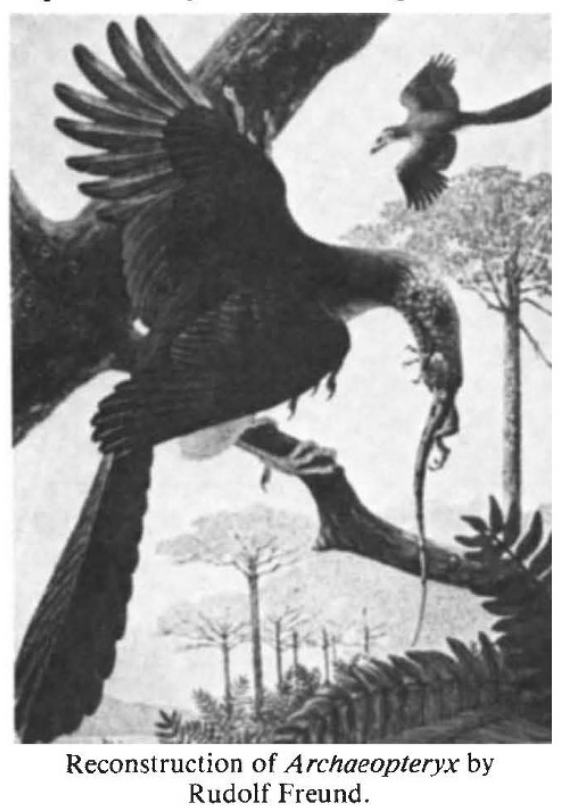

famous restorations by Heilmann, Charles Knight and others with which they appear. Many of these cry out for their original colours. Presumably the decision to exclude the use of colour was the publisher's rather than the author's; nevertheless I imagine that it will affect sales adversely. This is a pity as the book is otherwise well produced and certainly deserves an audience.

Alec Panchen, a vertebrate palaeontologist, is Reader in Vertebrate Zoology at the University of Newcastle upon Tyne.

\section{Gorillas on a tightrope}

\section{Alison Jolly}

The Natural History of the Gorilla. By A. F. Dixson. Pp.202. ISBN 0-297-77895-1. (Weidenfeld \& Nicolson: 1981.) £16.50. To be published in the USA by Columbia University Press.

IF YOU want to know about gorillas, you need this book. Alan Dixson has summarized the present state of knowledge about all aspects of gorillas' biology from anatomy to conservation. Furthermore, he writes in a lucid, factual style which presents the information clearly to anyone from fifth form to professorial status, without either talking down or jazzing up.
The drawings (by Dixson himself) add both clarity and charm.

The book has several strengths. First, it deals equally with the results of laboratory work and results from the field. Dixson's own studies range from laboratory analysis of primate hormones and sexual behaviour, through the testicular atrophy of several adult male silverbacks in zoos (including Guy at London), to making field censuses of gorilla populations. He is thus well placed to appreciate both sides of the story. A second strength is the balance achieved between generalization and data from individual studies. In the chapter "How Close to Man?", he manages to explain quickly many of the bases of primate classification, sum up the evidence which suggests man's close relationship to gorilla and chimpanzee and the more distant relationship of these three African species to orang-utans, and yet include the divergent studies which indicate Asiatic, rather than African, origins for man. Similarly, when he describes wild populations, he includes data showing differences between the three gorilla subspecies, and even between western and eastern Virunga Volcanoes, adding appropriate caution about sample size. In a popular book, it is unusual to avoid generalizations about "the gorilla" meaning ten or twenty individuals on Mount Visoke.

Finally, Dixson covers the whole scope of the literature from Hanno (fifth century BC) up to 1980 . This enables him to deal fairly with such experiments as Yerkes' on Congo (1926-1928), which is still one of the most complete accounts of a gorilla's problem-solving, as well as Redshaw's (1978) splendid Piagetian study of the development of infant gorilla intelligence. The conservation account is also up to date, to the death of Digit and others who had their heads and hands chopped off for tourist souvenirs.

The main reservation I have is that Dixson does not pursue his synthesis of detail quite far enough for my taste. I looked for a discussion of the relation of gorilla leaf-eating to metabolism, ranging and social structure, and comparison with the frugivorous orang and chimp. All the pieces are there, but Dixson does not explicitly link them up; similarly, reproductive strategy is split into several different chapters. This is clearly his choice - he gives us the data without fashionable theorizing, but he is better placed than most of us to deal with such theories.

I could also do with slightly more drama in the final chapter on conservation perhaps some of Dian Fossey's emotion over Digit, or Alan Goodall's encounters with poachers in The Wandering Gorillo (Collins, 1979). Instead, Dixson has chosen restraint. Perhaps he is right that estimates of the remaining wild populations and their possible or likely extinction are even more horrifying.

The whole question of how to balance professional against popular appeal bedevils primate studies. In the circumstances Alan Dixson's summary of the natural history of the gorilla for such a wide audience is laudable. Scholarly balance may seem faint praise until you add that it is balance on a very thin tightrope indeed.

Alison Jolly is temporarily in the School of Cultural and Community Studies, University of Sussex.

\section{Lure of the shore}

\section{J.T. Enright}

Intertidal Invertebrates of California. By Robert H. Morris, Donald P. Abbott and Eugene C. Haderlie with 31 contributors. Pp.920. ISBN 0-8047-1045-7. (Stanford University Press: 1980.) \$45 US only.

This is a book for those who find the California shoreline at low tide a place of beauty, wonder and interest, and who want information on the common animals that live there. [Preface].

THE west coast of North America has one of the most diverse temperate-latitude intertidal faunas in the world. In California that fauna provides research material for dozens of marine laboratories and learning material for hundreds of high schools, colleges and universities. Intertidal Invertebrates of California is aimed at that limited - some might say, provincial audience, but it could conceivably also lure naturalists from the entire world to view and study this showplace of diversity. Whether or not it eventually has that sort of incidental success, there is no question about its value and importance for the intended audience: every biologist, professional or amateur, who ventures into the California intertidal zone for the first - or the ten-thousandth - time should have this volume available.

Thanks to a grant from The David and Lucille Packard Foundation, the price is such that most users will be able to purchase their own copies. Even a first glance at the 200 photographic plates - all but three of them in colour, most with four to six separate portraits of the animals will persuade the prospective buyer that this book is a bargain. The majority of the photographs were taken by Morris, but nearly 50 other naturalists contributed to the handsome illustrations. This portion of the book will be particularly treasured by all who find the "shoreline . . . a place of beauty [and] wonder".

With the photographs as the bait, Abbott and Haderlie, together with 31 other contributors, have provided nearly 700 pages of text, bibliography and index for those "who want information". Some 750 species are treated in detail in the 24 chapters. For each of entry, the text provides the classification of the animal; a morphological description, including 